University of Wollongong

Research Online

Faculty of Engineering - Papers (Archive)

Faculty of Engineering and Information

Sciences

2005

\title{
Large upper critical field and irreversibility field in MgB2 wires with SiC additions
}

M. D. Sumption

Ohio State University, USA

M. Bhatia

Ohio State University, USA

M. Rindfleisch

Hyper Tech Research Inc, Ohio, USA

M. Tomsic

Hyper Tech Research Inc, Ohio, USA

Saeid Soltanian

University of Wollongong, saeid@uow.edu.au

See next page for additional authors

Follow this and additional works at: https://ro.uow.edu.au/engpapers

Part of the Engineering Commons

https://ro.uow.edu.au/engpapers/135

\section{Recommended Citation}

Sumption, M. D.; Bhatia, M.; Rindfleisch, M.; Tomsic, M.; Soltanian, Saeid; Dou, S. X.; and Collings, E. W.: Large upper critical field and irreversibility field in MgB2 wires with SiC additions 2005.

https://ro.uow.edu.au/engpapers/135 
Authors

M. D. Sumption, M. Bhatia, M. Rindfleisch, M. Tomsic, Saeid Soltanian, S. X. Dou, and E. W. Collings 


\title{
Large upper critical field and irreversibility field in $\mathrm{MgB}_{2}$ wires with SiC additions
}

\author{
M. D. Sumption ${ }^{\text {a) }}$ and M. Bhatia \\ Materials Science Department, The Ohio State University, Columbus, Ohio 43210 \\ M. Rindfleisch and M. Tomsic \\ Hyper Tech Research, Inc., Columbus, Ohio 43210 \\ S. Soltanian and S. X. Dou \\ Institute for Superconducting and Electronics Materials, The University of Wollongong, \\ Wollongong, NSW, Australia \\ E. W. Collings \\ Materials Science Department, The Ohio State University, Columbus, Ohio 43210
}

(Received 18 October 2004; accepted 7 January 2005; published online 25 February 2005)

\begin{abstract}
Resistive transition measurements are reported for $\mathrm{MgB}_{2}$ strands with $\mathrm{SiC}$ dopants. The starting $\mathrm{Mg}$ powders were 325 mesh $99.9 \%$ pure, and the B powders were amorphous, $99.9 \%$ pure, and at a typical size of $1-2 \mu \mathrm{m}$. The $\mathrm{SiC}$ was added as $10 \mathrm{~mol} \%$ of $\mathrm{SiC}$ to $90 \mathrm{~mol} \%$ of binary $\mathrm{MgB}_{2}$ $[(\mathrm{MgB} 2) 0.9(\mathrm{SiC}) 0.1]$. Three different $\mathrm{SiC}$ powders were used; the average particle sizes were 200 $\mathrm{nm}, 30 \mathrm{~nm}$, and $15 \mathrm{~nm}$. The strands were heat treated for times ranging from 5 to $30 \mathrm{~min}$ at temperatures from $675^{\circ} \mathrm{C}$ to $900{ }^{\circ} \mathrm{C}$. Strands with $200 \mathrm{~nm}$ size $\mathrm{SiC}$ additions had $\mu_{0} H_{\mathrm{irr}}$ and $B_{c 2}$ which maximized at $25.4 \mathrm{~T}$ and $29.7 \mathrm{~T}$ after heating at $800{ }^{\circ} \mathrm{C}$ for $30 \mathrm{~min}$. The highest values were seen for a strand with $15 \mathrm{~nm} \mathrm{SiC}$ heated at $725^{\circ} \mathrm{C}$ for $30 \mathrm{~min}$ which had a $\mu_{0} H_{\text {irr }}$ of $29 \mathrm{~T}$ and a $B_{c 2}$ higher than 33 T. (C) 2005 American Institute of Physics. [DOI: 10.1063/1.1872210]
\end{abstract}

It has been demonstrated that in some cases the irreversibility field, $\mu_{0} H_{\text {irr }}$, and upper critical field, $B_{c 2}$, of $\mathrm{MgB}_{2}$ can be enhanced from the values seen from the binary compound. This has been most evident in thin-film results, ${ }^{1-3}$ with $B_{c 2}$ reaching $49 \mathrm{~T}$ and even higher at $4.2 \mathrm{~K}$. This is understood to be due to increased scattering in the conductor, an effect seen in a number of materials but more pronounced for $\mathrm{MgB}_{2}$ because of its two-gap nature. ${ }^{4} \mathrm{~A}$ full understanding of just what material modifications enable the $B_{c 2}$ enhancement in champion $B_{c 2}$ films is lacking, however, one possibility seems to be lattice distortion induced in part by $\mathrm{C}$ substitution in the $\mathrm{B}$ sublattice. ${ }^{2}$ Several efforts to generate similar $B_{c 2}$ enhancements in $\mathrm{MgB}_{2}$ wires and bulks has been stimulated by these results. $\mathrm{A}$ number of researchers have investigated $\mathrm{C}$ doping in bulks ${ }^{5,6}$ to increase $\mu_{0} H_{\text {irr }}$ and $B_{c 2}$, which are, of course, strongly correlated (in this context, see Ref. 2), and more generally high-field properties in wires with $\mathrm{SiC}^{7-11}$ Bulk samples which had been exposed to excess $\mathrm{Mg}$ vapor showed high $B_{c 2}$ values as well, with a $B_{c 2}(0)$ estimate of $29 \mathrm{~T}^{2}$ Numerous other additives have also been investigated, ${ }^{12,13}$ in some cases with the express purpose of changing the $\mathrm{B}$ or $\mathrm{Mg}$ sublattice, or otherwise changing the electronic state of the system.

Given the variation in preparation conditions and the sensitivity of $\mathrm{MgB}_{2}$ critical fields to $\kappa$, there is some variation in the reported values of $\mu_{0} H_{\text {irr }}$ and $B_{c 2}$. Irreversibility fields for ex situ $\mathrm{MgB}_{2}$ tapes have been seen at $\approx 12 \mathrm{~T}$ for field perpendicular to the tape face ${ }^{14}$ [ex situ tapes are anisotropic such that $H_{\|} \approx 1.4 H_{\perp}$ (Ref. 15) due to partial alignment of the $\mathrm{Mg}$ and $\mathrm{B}$ planes parallel to the broad face of the tapes during rolling]. Suo and Flukiger found $\mu_{0} H_{\text {irr }}$ values of $8 \mathrm{~T}$ and $10.4 \mathrm{~T}$ in perpendicular and parallel orientations

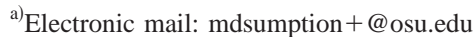

of the applied field, and, under the same orientations, $B_{c 2} \mathrm{~S}$ of 11.9 T and $15.1 \mathrm{~T}^{16,17}$ Recent results from Goldacker et al. ${ }^{18}$ would extrapolate to higher values at $4.2 \mathrm{~K}$. Matsumoto and Kumakura ${ }^{19}$ used $\mathrm{SiO}_{2}$ and $\mathrm{SiC}$ in the in situ process, enhancing $\mu_{0} H_{\text {irr }}$ from $\approx 17 \mathrm{~T}$ to $\approx 23 \mathrm{~T}$ at $4 \mathrm{~K} . \mathrm{ZrSi}_{2}, \mathrm{ZrB}_{2}$, and $\mathrm{WSi}_{2}$ additions were also attempted, ${ }^{20}$ with some increases seen. Hydride-based $\mathrm{MgB}_{2}$ powder with $\mathrm{SiC}$ dopants was also investigated, and seen to give $B_{c 2}$ values of $\approx 23 \mathrm{~T}^{21}$ Dou et al. $^{7-10}$ showed improved high-field critical current results for $\mathrm{SiC}$, and similar wires measured in this laboratory showed improvements in the apparent irreversibility field as might be extrapolated from transport results. ${ }^{11}$ In this work, strands of similar construction were investigated systematically, and high-field resistive transitions were used to demonstrate relatively large values of $\mu_{0} H_{\text {irr }}$ and $B_{c 2}$ with various kinds of $\mathrm{SiC}$ dopants under various heating conditions.

Round, monofilamentary, powder in tube (PIT) $\mathrm{MgB}_{2}$ strands were fabricated by continuous (described previously in Ref. 11) and standard powder in tube methods. The outer sheath was $\mathrm{Fe}$ enclosed in $\mathrm{Cu} 30 \mathrm{wt} \% \mathrm{Ni}$. The starting $\mathrm{Mg}$ powders were 325 mesh $99.9 \%$ pure, and the B powders were amorphous, $99.9 \%$ pure, and at a typical size of 1-2 $\mu \mathrm{m}$. For strands $\mathrm{A}$ and $\mathrm{B}$, the powders were mixed in a rotating V-shaped tube and then planetary milled. ${ }^{11}$ Coarse SiC $(200 \mathrm{~nm})$ powders were added during this process in the proportion $10 \mathrm{~mol} \%$ of $\mathrm{SiC}$ to $90 \mathrm{~mol} \%$ of binary $\mathrm{MgB}_{2}$ [(MgB2)0.9(SiC)0.1]. Strands C and D, fabricated at the University of Wollongong, were also made from an in situ route, in this case with $10 \mathrm{wt} \%$ of "fine" $\mathrm{SiC}$ powder (15 and $30 \mathrm{~nm}$ ). All strands were heated in flowing Ar at temperatures ranging from $640{ }^{\circ} \mathrm{C}$ to $725^{\circ} \mathrm{C}$ for $30 \mathrm{~min}$. Ramp-up and ramp-down times were short. Transport $J_{c}$ results for similar wires have been previously reported, ${ }^{11}$ val- 


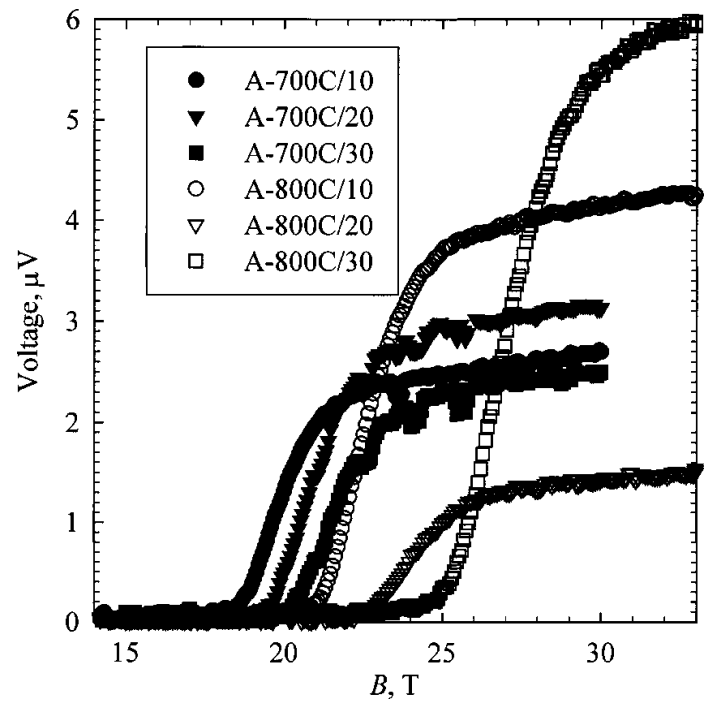

FIG. 1. Resistive transition (vs $B$ ) at $4.2 \mathrm{~K}$ for Strand A (200 nm SiC-doped $\left.\mathrm{MgB}_{2}\right)$.

ues for samples from Strand A of the present series gave 8 $\times 10^{4} \mathrm{~A} / \mathrm{cm}^{2}$ at $5 \mathrm{~T}$ and $4.2 \mathrm{~K}$.

Four-point transport measurements were made on $1 \mathrm{~cm}$ long samples at the National High Magnetic Field Laboratory in Tallahassee, Florida. Standard $\mathrm{Pb}-\mathrm{Sn}$ solder was used for forming the contacts on the outer sheath, and the distance between the voltage taps was $5 \mathrm{~mm}$. The applied current was $10 \mathrm{~mA}$, and current reversal was used. All measurements were made at $4.2 \mathrm{~K}$ in applied fields ranging from 0 to $33 \mathrm{~T}$. The samples were placed perpendicular to the applied field, values of $\mu_{0} H_{\text {irr }}$ and $B_{c 2}$ being obtained taking the $10 \%$ and $90 \%$ points of the resistive transition. Resistive transitions in self-field were used to obtain $T_{c}$ curves. In this case the samples were from neighboring sections of strand, and were $6 \mathrm{~cm}$ long, with voltage taps $3 \mathrm{~cm}$ apart.

Figure 1 shows the resistive transitions for Strand A after heating for various times at $700{ }^{\circ} \mathrm{C}$ and $800{ }^{\circ} \mathrm{C}$. It can be clearly seen that both $\mu_{0} H_{\text {irr }}$ and $B_{c 2}$ increase with increasing heating time and temperature in the ranges investigated. The results for Strand A are given in Table I. These results are significantly higher than those of earlier reports for binary $\mathrm{MgB}_{2}$ (for example, 8-10.4 $\mathrm{T}$ for $\mu_{0} H_{\mathrm{irr}}$ and $12-15$ for $\left.B_{c 2}\right) .{ }^{16,17}$ In particular, the $\mu_{0} H_{\text {irr }}$ and $B_{c 2}$ values for $800{ }^{\circ} \mathrm{C}$ and $30 \mathrm{~min}$ of $25.4 \mathrm{~T}$ and $29.7 \mathrm{~T}$ represent quite high $\mu_{0} H_{\text {irr }}$ and $B_{c 2}$ for $\mathrm{SiC}$ doped $\mathrm{MgB}_{2}$ strands. The $\mu_{0} H_{\text {irr }}$ values are also higher than might have been expected from the extrapolation of high-field critical current results using a Kramer method. ${ }^{11}$

The response of Strand B is shown in Fig. 2, where trends similar to those of Strand A are seen. Curves of $\mu_{0} H_{\text {irr }}$

TABLE I. $\mu_{0} H_{\text {irr }}(4.2 \mathrm{~K})$ and $B_{c 2}(4.2 \mathrm{~K})$ for Strand A $(200 \mathrm{~nm} \mathrm{SiC})$.

\begin{tabular}{lcccc}
\hline Sample name & Tracer ID & Heat treatment $\left({ }^{\circ} \mathrm{C} / \mathrm{min}\right)$ & $\mu_{0} H_{\mathrm{irr}}, \mathrm{T}$ & $B_{c 2}, \mathrm{~T}$ \\
\hline $\mathrm{A}-700 \mathrm{C} / 10$ & HTR398 & $700 / 10$ & 19.7 & 21.6 \\
$\mathrm{~A}-700 \mathrm{C} / 20$ & HTR398 & $700 / 20$ & 19.8 & 22.8 \\
$\mathrm{~A}-700 \mathrm{C} / 30$ & HTR398 & $700 / 30$ & 20.3 & 23.9 \\
$\mathrm{~A}-800 \mathrm{C} / 10$ & HTR398 & $800 / 10$ & 22.5 & 25.6 \\
$\mathrm{~A}-800 \mathrm{C} / 20$ & HTR398 & $800 / 20$ & 21.3 & 24.7 \\
$\mathrm{~A}-800 \mathrm{C} / 30$ & HTR398 & $800 / 30$ & 25.4 & 29.7
\end{tabular}

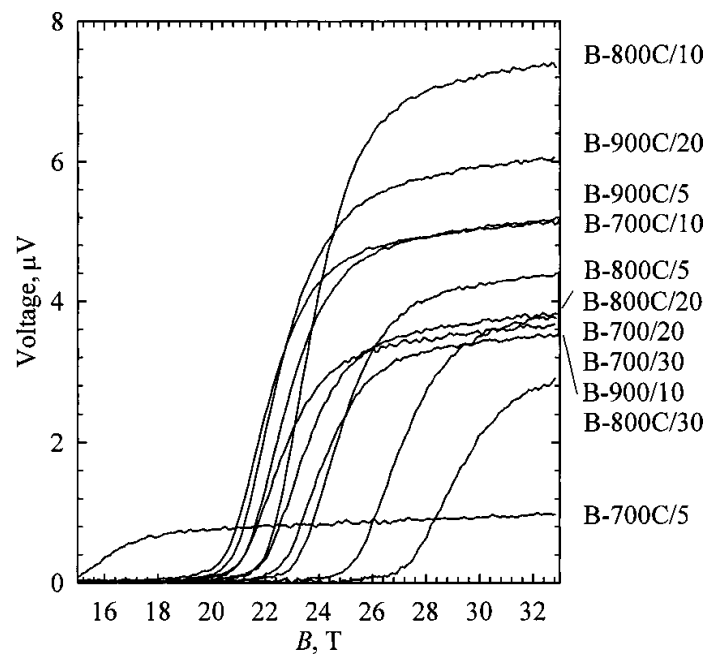

FIG. 2. Resistive transition (vs $B$ ) at $4.2 \mathrm{~K}$ for Strand B (200 nm SiC-doped $\mathrm{MgB}_{2}$ ). Lines are used here rather than individual data points for clarity.

and $B_{c 2}$ for Strand B heated at various temperatures are plotted versus heating time in Fig. 3. In this case, a $900{ }^{\circ} \mathrm{C}$ curve is also present, which is lower than the $800{ }^{\circ} \mathrm{C}$ curve. Heating at $800{ }^{\circ} \mathrm{C}$ for $30 \mathrm{~min}$ gives the highest values, $29.4 \mathrm{~T}$ and $31.3 \mathrm{~T}$ for $\mu_{0} H_{\mathrm{irr}}$ and $B_{c 2}$, respectively. The $T_{c}$ onset values (from resistive transitions under self-field) for the B-series samples heated for $5,10,20$, and $30 \mathrm{~min}$ at $800{ }^{\circ} \mathrm{C}$ were 34.2 $\mathrm{K}, 34.4 \mathrm{~K}, 37.8 \mathrm{~K}$, and $34.4 \mathrm{~K}$ respectively, with transition widths (as measured from $10 \%$ to $90 \%$ of the transition) of 1.2 to $1.4 \mathrm{~K}$. The $T_{c}$ value of about $33.2 \mathrm{~K}$ (for 10 and 30 min heatings) corresponds to an expected enhancement of $B_{c 2} \cdot{ }^{2}$ Overall, while $T_{c}$ is depressed from optimal values for $\mathrm{MgB}_{2}$, no strong systematic correlation is seen between $T_{c}$ and $B_{c 2}$ in these samples. This is likely to be due to inhomogeneity in the wire. It may be that various current paths exist, some of which have different compositions as well as different orientations of the $\mathrm{MgB}_{2}$ grains with respect to the external field. This interpretation would be consistent with the lower $\mu_{0} H_{\text {irr }}$ that has been extrapolated from higher current

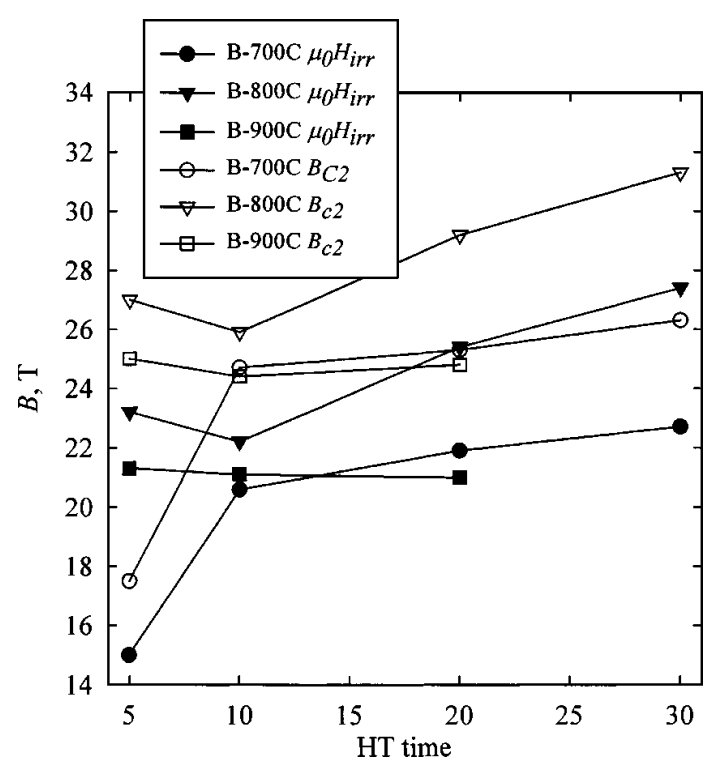

FIG. 3. Curves of $\mu_{0} H_{\text {irr }}(4.2 \mathrm{~K})$ and $B_{c 2}(4.2 \mathrm{~K})$ for Strand B heated at $700{ }^{\circ} \mathrm{C}, 800{ }^{\circ} \mathrm{C}$, and $900^{\circ} \mathrm{C}$ for various times.

Downloaded 14 Aug 2006 to 130.130.37.6. Redistribution subject to AlP license or copyright, see http://apl.aip.org/apl/copyright.jsp 


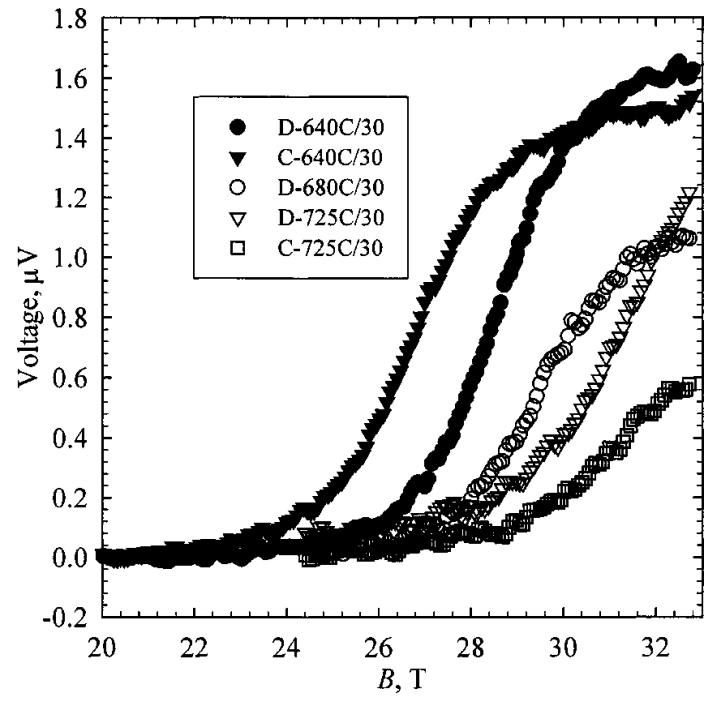

FIG. 4. Resistive transition (vs $B$ ) at $4.2 \mathrm{~K}$ for Strands C and D (15 nm and $30 \mathrm{~nm} \mathrm{SiC}$-doped $\mathrm{MgB}_{2}$ ).

transport measurements on these wires (note that significant "tails" were present). ${ }^{11}$

Figure 4 shows the resistive transitions for Strands C and $\mathrm{D}$ after various heating temperatures and times. These two strands had the smallest $\mathrm{SiC}$ powder sizes (at 15 and $30 \mathrm{~nm}$ average size). No clear distinction between the results of these two strands is seen, although as a group they have higher values of $\mu_{0} H_{\text {irr }}$ and $B_{c 2}$ than do Strands A and B containing the coarse SiC. The highest values are seen for higher temperatures within this set, consistent with the results of Strands A and B. The highest values seen were for Strand C $(15 \mathrm{~nm} \mathrm{SiC})$ which had a $\mu_{0} H_{\text {irr }}$ of $29 \mathrm{~T}$ and a $B_{c 2}>33 \mathrm{~T}$ (see Table II).

In this work, we have presented $\mu_{0} H_{\text {irr }}$ and $B_{c 2}$ for $\mathrm{MgB}_{2}$ strands with $\mathrm{SiC}$ additions made using PIT, in situ powder methods. Higher values of $\mu_{0} H_{\text {irr }}$ and $B_{c 2}$ were seen for strands heated at higher temperatures and, in some cases, longer times. Strands with finer $\mathrm{SiC}$ powders also had larger

TABLE II. $\mu_{0} H_{\text {irr }}(4.2 \mathrm{~K})$ and $B_{c 2}(4.2 \mathrm{~K})$ Strands C and D $(15 \mathrm{~nm}$ and 30 $\mathrm{nm} \mathrm{SiC)}$.

\begin{tabular}{ccclcc}
\hline \hline $\begin{array}{c}\text { Sample } \\
\text { name }\end{array}$ & $\begin{array}{c}\text { Tracer } \\
\text { ID }\end{array}$ & $\begin{array}{c}\text { SiC size } \\
(\mathrm{nm})\end{array}$ & $\begin{array}{l}\text { Heat treatment } \\
\left({ }^{\circ} \mathrm{C} / \mathrm{min}\right)\end{array}$ & $\begin{array}{c}\mu_{0} H_{\text {irr, }}, \\
\mathrm{T}\end{array}$ & $\begin{array}{c}B_{c 2}, \\
\mathrm{~T}\end{array}$ \\
\hline $\mathrm{D}-640 \mathrm{C} / 30$ & $\mathrm{~S} 1$ & 30 & $640 / 30$ & 26.4 & 30.4 \\
$\mathrm{C}-640 \mathrm{C} / 30$ & $\mathrm{~S} 2$ & 15 & $640 / 30$ & 24.2 & 28.2 \\
$\mathrm{D}-680 \mathrm{C} / 30$ & $\mathrm{~S} 3$ & 30 & $680 / 30$ & 27.0 & 31.2 \\
$\mathrm{D}-725 \mathrm{C} / 30$ & $\mathrm{~S} 5$ & 30 & $725 / 30$ & $\approx 28$ & $>33$ \\
$\mathrm{C}-725 \mathrm{C} / 30$ & $\mathrm{~S} 6$ & 15 & $725 / 30$ & $\approx 29$ & $>33$ \\
\hline \hline
\end{tabular}

$\mu_{0} H_{\text {irr }}$ and $B_{c 2}$ values. In particular, strands with $200 \mathrm{~nm}$ size SiC additions had $\mu_{0} H_{\text {irr }}$ and $B_{c 2}$ which maximized at $25.4 \mathrm{~T}$ and $29.7 \mathrm{~T}$ for strands heated at $800{ }^{\circ} \mathrm{C}$ for $30 \mathrm{~min}$. Strands with $15 \mathrm{~nm}$ and $30 \mathrm{~nm}$ additions had even higher values. The highest critical-field values were seen for a strand with 15 $\mathrm{nm} \mathrm{SiC}$ additions which after $725^{\circ} \mathrm{C}$ for $30 \mathrm{~min}$ had a $\mu_{0} H_{\text {irr }}$ of $29 \mathrm{~T}$ and a $B_{c 2}$ greater than $33 \mathrm{~T}$.

This work was supported by a State of Ohio Technology Action Fund Grant and by the U.S. Department of Energy, HEP, Grant No. DE-FG02-95ER40900.

${ }^{1}$ C. B. Eom, M. K. Lee, J. H. Choi, L. J. Belenky, X. Song, L. D. Cooley M. T. Naus, S. Patnaik, J. Jiang, M. Rikel, A. Polyanskii, A. Gurevich, X. Y. Cai, S. D. Bu, S. E. Babcock, E. E. Hellstrom, D. C. Larbalestier, N. Rogado, K. A. Regan, M. A. Hayward, T. He, J. S. Slusky, K. Inumaru, M. K. Haas, and R. J. Cava, Nature (London) 411, 558 (2001).

${ }^{2}$ A. Gurevich, S. Patnaik, V. Braccini, K. H. Kim, C. Mielke, X. Song, L. D. Cooley, S. D. Bul, D. M. Kim, J. H. Choi, L. J. Belenky, J. Giencke, M. K. Lee, W. Tian, X. Q. Pan, A. Siri, E. E. Hellstrom, C. B. Eom, and D. C. Larbalestier, I, Supercond. Sci. Technol. 17, 278 (2004).

${ }^{3}$ V. Ferrando, P. Manfrinetti, D. Marre, M. Putti, I. Sheikin, C. Tarantini, and C. Ferdeghini, Phys. Rev. B 68, 094517 (2003).

${ }^{4}$ A. Gurevich, Phys. Rev. B 67, 184515 (2003).

${ }^{5}$ R. A. Ribeiro, S. L. Budko, C. Petrovic, and P. C. Canfield, Physica C 384, 227 (2003).

${ }^{6}$ R. A. Ribeiro, S. L. Budko, C. Petrovic, and P. C. Canfield, Physica C 385, 16 (2003).

${ }^{7}$ S. X. Dou, A. V. Pan, S. Zhou, M. Ionescu, H. K. Liu, and P. R. Munroe, Supercond. Sci. Technol. 15, 1587 (2002).

${ }^{8}$ A. V. Pan, S. Zhou, H. K. Liu, and S. X. Dou, Supercond. Sci. Technol. 16, 639 (2003).

${ }^{9}$ S. X. Dou, A. V. Pan, S. Zhou, M. Ionescu, X. L. Wang, J. Horvat, H. K. Liu, and P. R. Munroe, J. Appl. Phys. 94, 1850 (2003).

${ }^{10}$ S. X. Dou, W. K. Yeoh, J. Horvat, and M. Ionescu, Appl. Phys. Lett. 83, 4996 (2003).

${ }^{11}$ M. D. Sumption, M. Bhatia, S. X. Dou, M. Rindfleisch, M. Tomsic, L. Arda, M. Ozdemir, Y. Hascicek, and E. W. Collings, Supercond. Sci. Technol. 17, 1180 (2004).

${ }^{12}$ V. Braccini, L. D. Cooley, S. Patnaik, D. C. Larbalestier, P. Manfrinetti, A. Palenzona, and A. S. Siri, Appl. Phys. Lett. 81, 4577 (2002).

${ }^{13}$ J. Wang, Y. Bugoslavsky, A. Berenov, L. Cowey, A. D. Caplin, L. F. Cohen, J. L. MacManus Driscoll, L. D. Cooley, X. Song, and D. C. Larbalestier, Appl. Phys. Lett. 81, 2026 (2002).

${ }^{14}$ G. Grasso, A. Malagoli, M. Modica, A. Tumino, C. Ferdeghini, A. S. Siri, C. Vignola, L. Martini, V. Previtali, and G. Volpini, Supercond. Sci. Technol. 16, 271 (2003).

${ }^{15}$ G. Grasso, A. Malagoli, D. Marre, E. Bellingeri, V. Braccini, S. Roncallo, N. Scati, and A. S. Siri, Physica C 378, 899 (2002).

${ }^{16}$ R. Flükiger, P. Lezza, C. Beneduce, N. Musolino, and H. L. Suo, Supercond. Sci. Technol. 16, 264 (2003).

${ }^{17}$ R. Flükiger, H. L. Suo, N. Musolino, C. Beneduce, P. Toulemonde, and P. Lezza, Physica C 385, 286 (2003).

${ }^{18}$ W. Goldacker, S. I. Schlachter, B. Obst, and M. Eisterer, Supercond. Sci. Technol. 17, S490 (2004).

${ }^{19}$ A. Matsumoto, H. Kumakura, H. Kitaguchi, and H. Hatakeyama, Supercond. Sci. Technol. 16, 926 (2003).

${ }^{20}$ Y. Ma, H. Kumakura, A. Matsumoto, H Hatakeyama, and K Togano, Supercond. Sci. Technol. 16, 852 (2003).

${ }^{21}$ H. Kumakura, H. Kitaguchi, A. Matsumoto, and H. Hatakeyama, Appl. Phys. Lett. 84, 3669 (2004) 